\title{
Cine policíaco del tardofranquismo: el thriller en el “período oscuro” del cine español (1969-1975)
}

\author{
José Luis LÓPEZ SANGÜESA \\ Facultad de Ciencias de la Información de la UCM \\ joseluislsanguesa@hotmail.com
}

Recibido: 30/07/2015

Aceptado: 12/09/2015

\section{RESUMEN}

Definición de la etapa de crisis del aparato cinematográfico franquista, llamada aquí "Período Oscuro" (1969-1975), discusión de la etiqueta de subgéneros aplicada al cinema bis de la época, y caracterización histórica del thriller español y de sus corrientes estéticas y conceptuales internas en dicho período. La acotación del período 1969-1975 es clarificada previamente ante el vacío historiográfico al respecto. Se caracteriza la crisis que tiene lugar en el "Período Oscuro", desde su comienzo oficial en 1969, que supuso el definitivo cierre de las políticas proteccionistas emprendidas por el Director General de Cinematografía García Escudero en 1962. Después se define y discute la etiqueta de subgéneros aplicada tradicionalmente al cine español de género de bajo presupuesto. Luego, se especifican, definen y analizan las diversas categorías dentro del thriller español de 1969-1975: se trata de categorías temáticas y argumentales, estéticas, o bien relacionadas con corrientes internacionales del policíaco europeo. Por último, se extraen las conclusiones pertinentes.

Palabras clave: Cine, Crisis cinematográfica, Período oscuro, Géneros cinematográficos, Postgéneros, Franquismo, Thriller, Policíaco, Techniscope, Novela popular.

\section{The Thriller in the "Dark Period” of Spanish Cinema (1969-1975)}

\begin{abstract}
Definition of the crisis period of the cinematographic pro-Franco device, hereby called "Dark Period" (1969-1975), discussion regarding the label of subgenres applied to the cinema bis from that time, plus historical characterization of the Spanish thriller and its aesthetic and conceptual trends in the abovementioned period.

The demarcation of the "Dark Period" 1969-1975 is previously clarified in the face of the historical void on this matter. The crisis that took place in the "Dark Period" is typified since its official beginning in 1969, which meant the definitive closure of the protectionist policies undertaken by the Managing Director of Cinematography García Escudero in 1962. Afterwards, the label "subgenres" traditionally applied to Spanish low-budget genres cinema is defined and discussed. Later, the different categories inside Spanish thriller of 1969-1975 are specified, defined and analysed: it's either about thematic, plot or aesthetical categories, or can be related to international currents of European Police cinema. Finally, the appropriate conclusions are draught.
\end{abstract}

Keywords: Cinema, Film crisis, Dark Period, Film genres, Post-genres, Franco era, Thriller, Police cinema, Techniscope, Pulp.

\section{Referencia normalizada}

López Sangüesa, J. L. (2015). “Cine policíaco del tardofranquismo: el thriller en el "período oscuro” del cine español (1969-1975)”. Documentación de las Ciencias de la Información Vol. 38. páginas. 265-284 


\section{INTRODUCCIÓN Y ESTADO DE LA CUESTIÓN}

Existe un considerable vacío en lo que atañe al estudio monográfico del período final de la cinematografía del franquismo (el que se corresponde con el definitivo abandono, desde 1969, de las políticas cinematográficas heredadas de García Escudero), y el cine de género de bajo presupuesto de la época únicamente ha recibido un tratamiento distante y peyorativo. Sólo el muy reciente estudio sociológico-cultural sobre cine de barrio en España, financiado por el Ministerio de Ciencia e Innovación (Huerta Floriano y Pérez Morán, 2012), y obras de algunos críticos y aficionados así como Pérez Bowie, 2013 (historiador cinematográfico especializado en adaptaciones literarias), sobre relaciones entre cine y literatura popular en el franquismo, se empiezan a ocupar de este último tema, aunque la mayoría de aproximaciones, o bien son obra de aficionados y carecen por consiguiente de verdadero interés científico, o bien sólo constituyen aproximaciones muy parciales a él, sin afán de exhaustividad ni de análisis de conjunto, o desde un prisma de análisis literario o sociológico que sigue sin comprehender la globalidad y que, por lo tanto, no interesa aquí. Ni siquiera la monografía por antonomasia sobre cinema bis español (Equipo Cartelera Turia, 1974) se ocupa del tema con pretensiones de analizarlo en toda su complejidad, sino que más bien lo despacha con sucesivas diatribas y una caracterización superada y discutible, amén de prescindir absolutamente del thriller de la época.

Por otra parte, cabe remarcar que el thriller español de los setenta (no digamos ya en todo en su devenir histórico global) carece de un estudio sistemático y completo que lo caracterice con el rigor pertinente.

En este estudio se quiere demostrar la entidad específica y complejidad del thriller español del período final del aparato cinematográfico franquista, tras describir brevemente las características de dicho período de cara a su operatividad para el estudio y la valoración histórica.

\section{METODOLOGÍA EMPLEADA}

Se ha recurrido a obras de referencia de historiadores cinematográficos diversos, así como a estudios de la época, y se han incluido datos cuantitativos para respaldar la caracterización histórica del período.

Para elaborar la filmografía se han consultado anuarios (los de Uniespaña del Sindicato Nacional del Espectáculo: 1969, 1970, 1971, 1972, 1974, 1975 y 1976), repertorios biográficos (el de Falquina, 1975), guías y diccionarios (Abajo de Pablos, 2001; Aguilar, 2006; Gasca, 1998; Riambau y Torreiro, 1998; Riambau y Torreiro, 2008); cronologías (Cebollada, 1996), bases de datos de internet (IMDB), y la revista profesional Cineinforme. Para la datación de los films se ha recurrido a la fecha del depósito legal (que se estima la más fiable dentro de la poca fiabilidad de las fechas de las producciones cinematográficas), bien a partir de los rótulos de crédito de las propias películas visionadas, bien a través de la data de los guiones depositados en la 
Biblioteca Nacional (cuando los hubiere) junto con fichas, guión definitivo y fotos de rodaje, para efectuar el susodicho depósito legal.

En total se han hallado 147 títulos asimilables al thriller, de los cuales se ha podido visionar 141 en instituciones oficiales (BNE, Filmoteca Española), internet o DVD doméstico. Se han anotado fichas técnico-artísticas, laboratorios, ratio de aspecto, procedimiento de rodaje, sistema de color, rasgos estéticos, conceptuales e ideológicos, y posibles referentes de cada película. Se ha elaborado un análisis cuantitativo de toda la filmografía elaborada, así como de las coproducciones internacionales y de aquellos films que utilizaron el sistema de rodaje Techniscope. Finalmente, se han agrupado los films analizados en categorías estéticas y conceptuales específicas según constantes repetidas, y se han extraído conclusiones globales de cada categoría.

\section{CARACTERIZACIÓN DEL PERÍODO}

\subsection{Definición}

La periodización por la que se ha optado estima que los rasgos específicos de la etapa 1969-1975 son los siguientes: 1) Grave crisis económica de nuestro cine, simultánea al predominio y decadencia de las coproducciones de bajo presupuesto. 2) Recrudecimiento de la represión censorial a partir del nombramiento de Sánchez Bella como Ministro de Información y Turismo. 3) Inestabilidad de las políticas cinematográficas y de la propia existencia administrativa de la Dirección General de Cinematografía. 4) Desaparición práctica del Nuevo Cine Español (cuyo testamento es el film colectivo Los desafíos (1968), y dificultades de integración de sus pupilos en el aparato cinematográfico del último franquismo. 5) Grave conflictividad política de la Escuela Oficial de Cinematografía, agudizada a partir de la práctica de Antonio Drove La caza de brujas, de 1967, y del Encuentro Internacional de Escuelas de Cine de Sitges, del mismo año, y agravada en el período estudiado, hasta la muerte de esta institución. 6) Radicalización y posterior hundimiento de la ASDREC, el sindicato de directores del verticalismo. 7) Predominio, y creciente declive, del cine de subgéneros. 8) Competencia ya considerable de la televisión, sobre todo a partir de 1969. 9) Decadencia de las salas de exhibición cinematográfica.

La etapa analizada, a la que aquí se denomina "Período Oscuro del cine español", se iniciaría en 1969 con la designación de Alfredo Sánchez Bella como Ministro de Información y Turismo, el declarado punto álgido de la crisis del cine español, y el cierre definitivo de la legislación abierta por García Escudero a partir de 1962. Y terminaría en 1975, con el inicio del "destape” -gracias a las nuevas y más permisivas Normas de Calificación-, la suavización de la censura, la muerte de las coproducciones, y la desaparición del general Franco. Se entiende que aquí se abre una nueva etapa política -de Transición, como se la ha venido en llamar-, en que la censura y la calificación administrativas no son ya tan determinantes, lo que incluso permitirá que 
se estrenen títulos antes prohibidos, como Canciones para después de una guerra, de Basilio M. Patino, o La prima Angélica, de Carlos Saura.

Varios de los rasgos aquí expuestos nacen con anterioridad al período analizado: se ha acotado este en función de unas características específicas, algunas de las cuales como el auge de las coproducciones de bajo presupuesto-, ya existían previamente. Pero la autonomía histórico-cinematográfica del recodo 1969-1975 proviene de la abierta y declarada entrada en crisis de las políticas franquistas en el ámbito de la cinematografía, y de la apertura final, pues, de lo que Monterde (1992) llamó una etapa de no-política cinematográfica, que se extenderá hasta la llamada Ley Miró de 1983. En 1975 se inicia el largo proceso de lo que se ha denominado Transición política.

La acotación del período topa con varios problemas: de un lado, su continuidad respecto del cine de género (o de subgéneros) cronológicamente previo (así por ejemplo, José María Zabalza rueda en 1969 una película de gángsters... cerrando un díptico temático abierto el año anterior -esto es, fuera de período-); y del otro, la práctica carencia de una historiografía del cine español genérico de bajo presupuesto, infamado con la etiqueta de subgenérico, que luego se caracterizará y discutirá oportunamente. El período aquí establecido no es, ni puede ser, un compartimento cerrado, estanco, una estancia inamovible con fronteras rígidamente delimitadas.

\subsection{Un período de crisis}

El fracaso de las políticas aperturistas de José María García Escudero en el período 1962-1967, lleva a una posición defensiva del aparato del Estado franquista y a un progresivo recrudecimiento de la represión censorial, que se reflejará fuertemente en la etapa 1969-75. La escasa acogida en taquilla del cine de los protegidos del Director General -los miembros del llamado Nuevo Cine Español (NCE): Carlos Saura, Mario Camus, Basilio M. Patino, Francisco Regueiro, Manuel Summers, etc., y la difícil o imposible integración de algunos de ellos -Jesús García de Dueñas, Raúl Peña, Víctor Erice, y otros- en el aparato cinematográfico español durante los años 1962-1969, clausuran el experimento de protección oficialista de los egresados de la cada vez más conflictiva Escuela Oficial de Cinematografía (EOC). Según Casimiro Torreiro (en Gubern et al., 2009, pp. 335-336), El juego de la oca, de Summers, estuvo en el puesto 108 de recaudación de su año correspondiente; Nueve cartas a Berta, de Patino, en el 334; La caza, de Saura, en el 536; Juguetes rotos, de Summers, en el 862; y De cuerpo presente, de Eceiza, en el 870.

Además, la torpe legislación (el 15\% automático de recaudación en taquilla para las coproducciones, sin especificar el índice de participación española requerido, desencadenó una oleada de "falsas coproducciones" que vaciaron el Fondo de Protección a la Cinematografía destinado a las ayudas) producirá la quiebra del sistema de subvenciones ideado por el propio Escudero (Op. cit., p. 338). Añádase a ello la mala comercialización de nuestro cine, la deficiente labor de promoción 
exterior de Cinespaña, o los permanentes fraudes al control de taquilla para obtener subvenciones (mediante el truco de "reventar la taquilla", consistente en comprar entradas para inflar artificialmente el cupo de espectadores cara al Estado) (Monterde, 1992, p. 30). A resultas de todo ello y de los “desórdenes” en la EOC, ya evidentemente fracasada como intento de aparato ideológico franquista, Escudero será cesado en noviembre de 1967, so pretexto de una reorganización administrativa del Ministerio de Información y Turismo.

Le sucedió en el cargo el cuñado de Fraga, Carlos Robles Piquer, que disminuyó las ayudas e incrementó la represión censorial (Op. cit., p. 339; y Falquina, 1975, p. 173). Sin embargo, la legislación permanecería prácticamente invariable hasta 1969.

Entre 1969 y 1973, la cartera de Información y Turismo sería desempeñada por el nacionalcatólico y opusdeísta ultramontano Alfredo Sánchez Bella, que intervino el Banco de Crédito Industrial y bloqueó los fondos de ayudas a la cinematografía debido al escándalo Matesa (el monumental fraude del industrial catalán Vilá-Reyes, que se benefició de miles de millones de pesetas en créditos estatales para establecer una empresa de fabricación de telares para exportación... que nunca llegó a exportar). Como consecuencia directa de ello, hacia 1970 el Estado adeudará a los productores unos 230 millones de pesetas, cantidad que creció y cuyo pago se fue fraccionando y dilatando a lo largo de varios años (Casimiro Torreiro, en Gubern et al., 2009, pp. 342 y 348). La Dirección General de Cinematografía fue degradada a Subdirección en la estructura administrativa del Ministerio, y subsumidas sus competencias en la Dirección General de Cultura Popular. Como responsable de la misma fue designado Enrique Thomas de Carranza, quien suprimiría la calificación de "interés especial” y establecería un sistema de puntos de valoración por parte de una Comisión de Apreciación (de 1 a 10, valiendo cada punto 400.000 pesetas en 1971, y 700.000 en 1976), para con ello asegurar el control político-ideológico del cine español (Op. cit., pp. 348-349). La subvención automática del 15\% fue reducida al 10\%.

En la etapa de Sánchez Bella en el poder, se multiplicaron los atropellos de la censura: los tres casos más célebres fueron los del bloqueo de La prima Angélica, de Saura, la prohibición de Canciones para después de una guerra, de Patino (1971), por Carrero Blanco, y los 64 cortes a La semana del asesino (1972), de Eloy de la Iglesia.

En 1973, desempeña efímeramente la cartera de Información y Turismo el también opusdeísta Liñán y Zofío, que restablece la Dirección General de Cinematografía y el 15\% de subvención automática, e incrementa el Fondo de Protección a la Cinematografía (cuya deuda con los productores españoles había alcanzado ya los 500 millones) (Monterde, 1992, p. 30).

La maniobra aperturista del Gobierno Arias Navarro -a través del "Espíritu del 12 de febrero"- permite que se estrene La prima Angélica...

En febrero de 1975, con Pío Cabanillas en el Ministerio, se promulgan unas nuevas Normas de Calificación Cinematográfica, principalmente diferenciadas de las anteriores en que se consentía el desnudo por exigencias del guión (Op. cit., p. 32). 
Otro de los aspectos más reseñables del período analizado es la ruptura de la continuidad establecida entre la Escuela Oficial de Cinematografía (EOC) y el mundo profesional, por la creciente conflictividad política de la institución. La EOC, fundamental en el período 1962-1967 como plataforma de aplicación de las políticas administrativas de promoción del NCE, se derrumbará en la etapa estudiada aquí, ya en permanente enfrentamiento con la censura y la Policía. La Escuela sería teóricamente suprimida por el Decreto 2070/ 1971, de 9 de agosto (Vallés Copeiro del Villar, 1992, p. 144).

La ASDREC, organización sindical cinematográfica ideada por elementos antifranquistas encabezados por Juan Antonio Bardem, para infiltrar el verticalismo, ganará combatividad durante el período (sobre todo con su asamblea de 1970, donde se pedirá la libertad de expresión, la abolición de la censura, del doblaje y de la obligatoriedad del NODO, etc.), pero se derrumbará en 1975 como consecuencia de un fraude en las votaciones internas durante las elecciones sindicales, para situar en su presidencia al cineasta del Régimen César F. Ardavín (Hernández y Revuelta, 1976, p. 71).

Asimismo, en el "Período Oscuro" (e, incluso, desde inmediatamente antes) se da, en conjunción con la referida crisis, un predominio de las coproducciones internacionales: en 1967, de 125 películas en total, 70 eran coproducciones; pero al finalizar el período (1975), esta forma de producción ya está prácticamente muerta en España (Monterde, 1992, pp. 29 y 36; y Vallés Copeiro del Villar, 1992, p. 133). No obstante, este predominio es engañoso, pues durante el período analizado tiene lugar la decadencia de la fórmula, decadencia pareja con la crisis de las políticas de fomento de la cinematografía. Así, habían ido aumentando gradualmente desde las 24 de 1962 (año de la entrada de García Escudero en la Dirección General), hasta las 98 de 1965. De ahí descienden a las citadas 70 de 1967, y de ahí, tras varias oscilaciones (que alcanzan su punto crítico en 1969), a las 43 de 1971. Tras varias fluctuaciones más, caerán de 41 en 1974, a 21 en 1975 (Op. cit., pp. 102, 133 y 154).

Otro aspecto a tener en cuenta es la ya considerable competencia del medio televisivo hacia 1969. Ese año, el I Informe Foessa cuantificó que el 62 \% de los hogares ya tenían televisión. La audiencia de 1970 fue estimada por TVE en torno a los 15 millones de espectadores diarios. La desaparición legal del impuesto de lujo por tenencia de receptor en 1965 había favorecido un ingente incremento de las ventas de aparatos (José Carlos Rueda Laffond, 2005, p. 55). A ello cabe añadir el consumo de televisión a través de teleclubs (promovidos a partir de 1964 por el Ministerio de Información y Turismo, según parece, a imitación de una iniciativa del III Reich de 1942) y, sobre todo, de casas de vecinos y bares (Op. cit., pp. 57 y 59). Es precisamente desde 1969 que el consumo de receptores de televisión pudo incidir en el número de salas de exhibición de manera inmediata. Así, de 1965 a 1968 inclusive, el parque de salas se mantiene en 7.207, y en 1969 ha ascendido a 7.233: pero, a partir de 1970, irá descendiendo gradualmente hasta las 5.076 de 1975. El dramático descenso continuará después... (Hueso Montón, 1991). 
Según el sociólogo José Luis de Zárraga, los costes de la cinematografía habían aumentado en 1974 un 61'2\% respecto al sexenio 1965-1971 (José Luis de Zárraga, en V.V.A.A., 1975, p. 27). De Zárraga divide la producción de films en España en películas caras (equipo de primera clase, 7-8 semanas de rodaje, coste de 10-15 millones de pesetas), películas medias (equipos de primera y segunda categoría, 5 semanas de rodaje, 6’5-9 millones de pesetas), películas baratas (equipos de segunda y tercera categorías, 4 semanas de rodaje, 4-5 millones de pesetas), y películas extrabaratas (equipos de tercera categoría, tres semanas de rodaje, de 3 a 3’5 millones de pesetas).

El 60\% de las películas coproducidas en 1970 caían en las categorías de extrabaratas y baratas. Un buen número de las primeras se rodaron con un coste de apenas 3 millones de pesetas, en serie y completamente en exteriores, en unos tiempos aparentemente inverosímiles, y en conjunto, la coproducción española es de tan baja calidad que abochorna a cualquier profesional. (Op. cit., p. 26).

En el ámbito de las coproducciones, 16 productoras con rendimientos de taquilla superiores a los cien millones de pesetas suman el 56\% de los rendimientos totales, mientras que las 161 productoras menores recaudan sólo un $20 \%$ de tales rendimientos (Ibíd., p. 37).

Predominaba, pues, la coproducción, el cine barato, lo que se ha venido en denominar -con muy discutible calificación- los subgéneros. Este era indudablemente un cine de productor, de encargo, de finalidad estrictamente comercial y crematística. El negocio del mal llamado celuloide subgenérico en España llevará, por su propio volumen, al auge de estudios de rodaje nacionales y distribuidoras autóctonas, que posteriormente, con la caída de las coproducciones, se sumirán en un declive ininterrumpido que llega hasta hoy, con la práctica ausencia de un mercado real de distribución de nuestro cine...

\section{CINE DE SUBGÉNEROS Y THRILLER}

\subsection{Caracterización teórica del “cine de subgéneros” en la época}

Debido a la angosta situación económica de nuestra cinematografía por aquel entonces, la casi totalidad de films comerciales de género se realizarán en condiciones apuradas y dudosas, dentro de lo que se ha venido en definir como "cine de subgéneros.” Ya a lo largo del período analizado se dará una caracterización conceptual de lo subgenérico. Esta se deberá, por un lado, a la publicación especializada Nuestro Cine (1961-1971), y, por el otro, a la valenciana editorial Fernando Torres, creada a principios de los 70 para difundir obras de análisis textual y cultural, con especial predilección por lo cinematográfico. En el prólogo de un libro colectivo publicado por esta, Cine español, cine de subgéneros (Equipo Cartelera Turia, 1974), Román Gubern viejo colaborador de Nuestro Cine- proporcionaba una conceptualización del celuloide subgenérico, que, tanto por algunas sagaces observaciones, cuanto por su tono 
abiertamente peyorativo, resulta especialmente ilustrativa de la visión de la historiografía y la crítica respetables acerca de estas corrientes fílmicas, en los últimos cuarenta años. GUBERN arrancaba con estas palabras:

Debo comenzar este prólogo con la declaración autocrítica de ser un consumidor muy ocasional de los subgéneros del cine español, pues el hastío ha podido finalmente más que mi imperativo de información acerca de la cinematografía nacional. (...)

Estos subgéneros representan hoy el mayor y más rentable negocio de la producción cinematográfica española (Op. cit.: 11).”

Más adelante realizaba una interesante caracterización del subgénero a la sombra de la crisis de la industria cinematográfica internacional y su política de géneros:

El desplome mundial de los géneros afectó también a nuestra industria, pero como ninguna industria cultural, en función de su producción seriada, puede vivir escapando a los modelos repetitivos, nacieron así nuestros subgéneros. (...)

Los subgéneros son, como su propio nombre indica, sucedáneos miméticos y repetitivos de otros modelos previos, también repetitivos pero de carácter genuino y arquetípico. (...)

Y cuando un director español aborda un estereotipo de cine terrorífico, no remite su inspiración a las fuentes del Romanticismo inglés o alemán, sino a los productos ya estereotipados que cubren al ciclo cinematográfico República de Weimar-Productora Universal-Hammer Film. (Ibíd., pp. 12-13).

Detrás de todas estas definiciones se esconden, no obstante, juicios de valor que pretenden no ser tales, sino pasar por afirmaciones perfectamente “objetivas”. Así, se habla de la exportación de este cine a circuitos de sesión continua del extranjero tildando a estas salas de "subcines especializados y homologables a los porno-cines, que todavía no existen en España, pero que tienen ya sus sucedáneos.” (Ibíd., p. 13). Posteriormente, se dice del terror subgenérico que está "concebido como una pornografía de la crueldad”, y que es equiparable con el cine pornográfico en su tanatismo, un erotismo de la muerte cuya morbidez exhibicionista posee un fuerte componente psicoanalítico (un análisis este, no carente de interés y acierto, por otro lado). Estas violentas valoraciones (y las de la revista Nuestro Cine entre 1968 y 1971, tratando con especial crueldad a cineastas como Joaquín Romero Marchent, justamente exonerado decenios después) formaban parte de un entramado ideológico -el Cine como Arte frente al subcine, derivación espúrea, remedo y excrecencia del anterior- que tendrá consecuencias en la llamada Ley Miró de 1983, con su durísima legislación contra el porno y su retirada masiva de subvenciones al cine de bajo presupuesto guiada de criterios abiertamente subjetivistas. 
La conclusión de GUBERN no puede ser más lapidaria: "No resta más que decir que esta deleznable producción hispana no pasará jamás a las historias del cine (...)” (Ibíd.: 15).

Por supuesto, la excomunión, no ya de una película, sino de toda una corriente fílmica, temporalmente localizada, y con todo un aparato económico y un amplio público alrededor, no puede ser más insensata, y viene a explicar casi por sí sola la grave carencia de una historiografía global sobre toda una etapa del cine español (1969-1975), que incluso está desposeída de una periodización científica concreta...

Cabe añadir que el thriller, corriente cuantitativamente importante en el período estudiado, no está contemplado en el aludido libro de la editorial levantina, ni siquiera para despreciarlo. Acaso sea el único subgénero no citado siquiera en la única monografía sobre subgéneros existente en nuestro país a lo largo de varias décadas...

¿Cuán discutible puede ser la denominación de "subgénero"?

En primer lugar, se trata de una calificación peyorativa, estigmatizadora, que hace referencia a la naturaleza imitativa y sucedánea de las obras o productos de que se habla. Pero más adelante se verá que dentro del cine genérico español de bajo presupuesto, hay algunas obras que continúan consciente y deliberadamente corrientes autóctonas (como el thriller barcelonés de los 50, que hallará pervivencias durante el "período oscuro" a través de cineastas originarios de la factoría Iquino, como Juan Bosch y José Antonio de la Loma). También se verá que diversas obras utilizan la forma fílmica genérica como vehículo de inquietudes sociopolíticas (tal es el caso de los -por otra parte, muy destacables- films criminales de Eloy de la Iglesia y Jesús García de Dueñas, de Una vela para el diablo, de Eugenio Martín, de Hay que matar $a$ B, de José Luis Borau, o de la interesante Metralleta Stein, de José Antonio de la Loma, que continuaba la estela alegórica de A tiro limpio, de Pérez-Dolz...)

En segundo lugar, la etiqueta alude a la baja calidad de los productos automáticamente encuadrados en ella, haciendo tabula rasa de las variadas excepciones a la regla, constituidas por obras de digna factura y sólida construcción, como sucede con las películas de De la Iglesia y García de Dueñas, Metralleta Stein, de De la Loma, Alta tensión, de Julio Buchs, Tarot, de José María Forqué, Marta, de José Antonio Nieves Conde, La muerte del escorpión, de Gonzalo Herralde, Los fríos ojos del miedo, de Enzo G. Castellari, etcétera.

En tercer lugar, la pretensión de que únicamente la cinematografía española del aparato franquista en crisis viene a integrar corrientes prototípicas del exterior, es falsa: tanto las coproducciones en sí, como corrientes fílmicas de toda Europa Occidental, lo desmienten. El Krimi alemán, el giallo y el poliziesco italianos, son ejemplos de corrientes autóctonas de bajo presupuesto, impronta genérica y fuerte influjo de los éxitos recientes principalmente norteamericanos -y de clásicos con una intensa carrera comercial, como Hitchcock-, que vienen a impugnar la afirmación, más o menos emboscada, del cine subgenérico hispano como la acomplejada plasmación indígena de una frustrada imitación cosmopolita de lo ajeno. Los subgéneros españoles se integran en el mosaico internacional de una (ya indicada por Gubern) crisis y 
redefinición de la política periférica (no-hollywoodiense) de géneros, y su mercado. Pero esta aceleración y degradación económicas de la producción de cine comercial de género (con su correlato de crisis estética y conceptual) no puede denominarse propiamente serie $B$ : es tan sólo el acortamiento, crisis, y forzoso abaratamiento, del proceso de producción y consumo de cine conforme a la mentalidad colectiva de la época: la sala cinematográfica como lugar de pasatiempo y reunión social, y la apetencia de un cinema definido por patrones ya conocidos y compartidos (una de terror, una de vaqueros...) Así, el estudio de esta cinematografía de consumo viene a marcar el período final de estas formas específicas, ya completamente extintas y hasta lejanas, de consumo popular de películas.

En cuarto lugar, la estigmatización del subgénero y su gueto crítico-historiográfico correspondiente, vienen incluso a oscurecer determinados tramos de la carrera profesional de cineastas respetados: así, el conocimiento de la obra de Forqué, Bardem, Nieves Conde, Aranda, Grau, o el guionista Azcona, se ve repentinamente cuajado de "hiatos", de puntos oscuros debidos a la ignorancia o al subterfugio, porque caen dentro del círculo maldito de una corriente rechazada.

Por último, el celuloide de género de la época estudiada aún tenía referentes inmediatos en el clasicismo (por diversas razones: el proceso de formación de muchos profesionales, o el entonces todavía notorio consumo de reposiciones a través de los llamados cines de temporada, por ejemplo). Pero es obvio que su circunstancia económica no le permitía imitar los procedimientos de trabajo de la gran industria, el sistema de estudios, etc. De modo que crearía los suyos propios. El ejemplo más cristalino al respecto es el del sistema superpanorámico, 1: 2'35 (de rodaje y película esféricos y positivado anamórfico), Techniscope, creado exclusivamente para este tipo de cine (de manera similar a como el rodaje en Super $16 \mathrm{~mm}$. y 1: 1'68, para posteriormente hinchar a $35 \mathrm{~mm}$. panorámico, fue durante algún tiempo patrimonio exclusivo de las "nuevas cinematografías" de los 60). Además, el Techniscope facilitaba un considerable ahorro de superficie de negativo (ideal para una época de crisis profunda), puesto que sólo empleaba dos perforaciones por banda. Esta especificidad tecnológica de cada corriente fílmica en adecuación a sus imperativos económicos, técnicos y estéticos, está exigiendo de suyo un estudio pormenorizado, que aún, por desgracia, no es momento de ofrecer aquí.

En conclusión a este apartado, debe afirmarse que toda una corriente de la industria cinematográfica internacional está siquiera sin nombrar, sin denominación propiamente científica. Subgéneros no es válido por su carga peyorativa; serie $Z$ por la misma razón; serie $B$ tampoco, pues no corresponde a esta etapa histórica del cine comercial barato (sino más bien a la del sistema clásico de estudios); y cine de género de bajo presupuesto es demasiado vaga... La discusión de esta nomenclatura y la propuesta de alternativas son de tal complejidad, que, por supuesto, exceden los modestos límites de este trabajo. Su interés, aquí, radica en el tratamiento predominantemente despreciativo o incluso de omisión, efectuado por críticos e historiadores ante las corrientes comentadas. 


\subsection{Tendencias en el thriller español (1969-1975)}

El desconocimiento de lo que atañe a casi todo el thriller español del período estudiado (con algunas, contadas, excepciones: De la Iglesia, De la Loma, Isasi), no obsta para que se tratase de una corriente extraordinariamente prolífica: 147 títulos (incluyendo once parodias) en tan sólo siete años. Téngase en cuenta que en lo que se considera la Edad Dorada del thriller español, los años 50, "sólo" se realizaron 79 thrillers en diez años, de 1949 a 1959 (se realiza el recuento por la filmografía de Medina, 2000).

Asimismo, de estas 147 películas, 78 (aproximadamente un 53\%) son coproducciones internacionales. Si se lleva a cabo un análisis cuantitativo por años (Gráfico 1), podrá verse la evolución del thriller como índice de la del cine comercial de género en la época. De estos 147 thrillers, 20 (en torno a un 14\%) se realizan en 1969; 21 (otro 14\%) en 1970; 17 (un 11\% aproximado) en 1971; 23 (un 16\% aproximado) en 1972; 32 (alrededor de un 22\%), en 1973, el año más prolífico de este período; 22 (y un 15\% aproximado) en 1974; y, por último, sólo 12 (un 8\% aproximado) en 1975, clara señal de declive del cine español de género en este año.

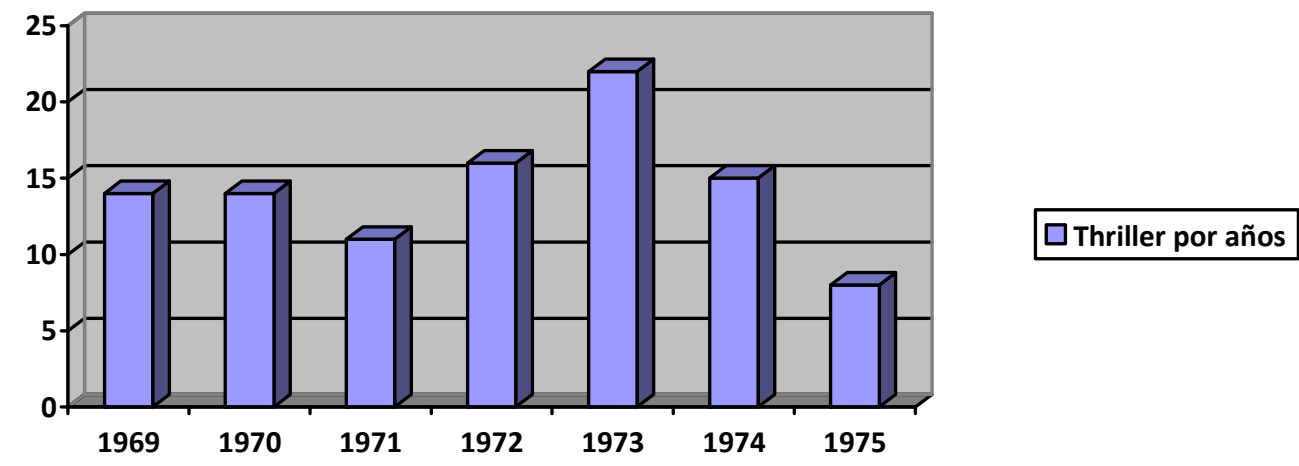

Gráfico 1: Producción anual de thriller

De un total de 78 thrillers en régimen de coproducción internacional en 7 años, 9 (un 12\% aproximado) se realizaron en 1969; 12 (alrededor de un 15\%) en 1970; 15 (un 19\% aproximado) en 1971; otros 15 (y otro 19\% aproximado) en 1972; 17 (en torno a un 22\%) en 1973; 9 (un 12\% aproximado) en 1974; y tan sólo dos (en torno a un 2\%) en 1975, lo que viene a corroborar la afirmación de Monterde sobre la práctica muerte de las coproducciones en ese año (Gráfico 2). 


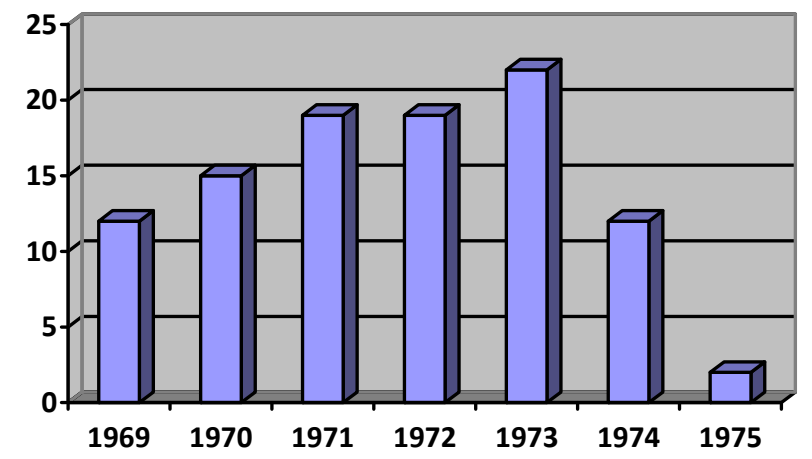

Gráfico 2: Coproducción de thriller por años

En el primer caso, se observa que el año más prolífico del thriller español del período oscuro” es 1973, con 32 películas (un 22\% aproximado) sobre un total de 147, y que el menos prolífico es 1975, con un ínfimo porcentaje de un 8\%.

En el caso de las coproducciones internacionales, se aprecia que el año más prolífico es también 1973, con 17 películas y un 22\% aproximado sobre un total de 78; que, dentro del período estudiado, se da un recodo de esplendor de las coproducciones internacionales entre 1970 y 1973; que se produce una brusca caída del 10\% en 1974, en que la tendencia se mantiene por encima del umbral de 1969; y, por último, un derrumbe total (de otro $10 \%$ respecto al año anterior) en 1975, año de la práctica muerte de esta modalidad de producción en nuestro país. Asimismo, y para que se pueda comprobar la importancia del arriba invocado sistema Techniscope, ha de tenerse en cuenta que de un total de 147 películas, 35 (un 24\% aproximado) se rodaron bajo este procedimiento. Ello puede llevar a varias conclusiones (aparte de la, desoladora, mengua o carencia de una necesaria historiografía técnica y tecnológica del cine en nuestro país): se trataba de una competencia con el espectáculo cinematográfico hegemónico (hollywoodiense) aprovechando, imitando, su propio lenguaje espectacular (el bigger than life de los formatos superpanorámicos), empero bajo la servidumbre de una cierta, ineludible, penuria presupuestaria. Pero también se trataba de una competencia con el amenazador adversario catódico. Recuérdese el origen de las ratios superpanorámicas: la competencia del medio televisivo y de factores como el nuevo modus vivendi de los barrios residenciales de extrarradio urbano en la Norteamérica de los años 50. En España, en que ese auge del esplendor consumista aún estaba erizado de contradicciones sociales propias del subdesarrollo, la televisión (sinécdoque del consumismo en general) no comenzó a constituir una asechanza seria para el cine hasta mediados-finales de los 60. Por lo tanto, el bigger than life cinematográfico hispánico (barato, precario, periférico... subdesarrollado) arribó tardíamen- 
te a nuestra sociedad, pues corrió parejas con una irrupción masiva, asimismo ejemplarmente tardía, del consumo popular de receptores de televisión.

En el seno de esta corriente genérica específica dentro del más amplio -y a la sazón predominante- celuloide eminentemente comercial y de productor, se dan fenómenos curiosos de caprichosas concomitancias temáticas entre varios films. Ello se repite en numerosas ocasiones, lo que viene a ser un barómetro, tanto de las pretensiones puramente industriales de aquel cinema (de rutinización, pues, y de producción de prototipos a reproducir ampliamente), como de su naturaleza fílmica de explotación de recientes éxitos ajenos o de fórmulas que ya habían demostrado su eficacia comercial. El extraño y tortuoso mapa de estas tendencias, comprobadas sobre el terreno y halladas inesperadamente y a posteriori, ha obligado al autor de estas líneas, a adoptar una terminología sui géneris para poder describirlas (por supuesto, tal clasificación no puede ser tajante, y se producen interferencias entre unas categorías y otras). Así:

\subsubsection{Híbridos genéricos}

Como señal de la crisis de la política de géneros arriba reseñada por Gubern, se observará una acusada propensión a hibridar entre sí elementos propios de géneros dispares, hasta el punto de que resulta extremadamente difícil la catalogación genérica tradicional si se aplica a films de la época. Un ejemplo que se repite particularmente es el de la mezcolanza entre policíaco y aventuras con ambientación exótica (Cuatro desertores (1969), de Pascual Cervera; Vuelo al infierno (1970), de Jesús Franco; Cobras humanas (1971), de Adalberto Albertini; Kill! (1971), de Romain Gary; El clan de los inmorales (1973), de José G. Maesso; Vacaciones sangrientas (1973), de Juan Jaime Bernós; y Las violentas (1974), de Fernando Miranda), todas ellas dentro de la moda epocal del thriller cosmopolita. Pero la tendencia más amplia fue la de la mezcla entre thriller y melodrama, casi siempre con una excusa moralizante: Algo amargo en la boca (1969), de Eloy de la Iglesia; Hembra (prohibido) (1970), de César F. Ardavín; etcétera.

El melodrama, por supuesto, era el relato más apropiado para un cine en su mayor parte explícitamente discursivo, parabólico y moralizante (recuérdese el fuerte melodramatismo de títulos del cine propagandístico español, como Raza, Locura de amor o Murió hace quince años). Los demás ejemplos de hibridación serán más aislados y erráticos: los elementos de policíaco y horror en Una vela para el diablo (1973), de Eugenio Martín (sátira feroz de la retrógrada y aislante cerrazón mental de la España católica y franquista); horror, ciencia-ficción y thriller en Las ratas no duermen de noche (1973), de José Luis Madrid; ciencia-ficción y thriller en Una gota de sangre para morir amando (1973), de Eloy de la Iglesia; etcétera. A menudo, y como otra señal destacable de esa crisis de las políticas genéricas, la adscripción de algunas películas a uno u otro género concreto se revela complicada. Así, algunos de ellos incluyen elementos de thriller, pero los elementos predominantes son otros.

Según Casilda de Miguel (1991, pp. 94-96): 
El cine, desde los setenta, parece presentar un estado de anarquía, o mejor aún de eclecticismo formal, que afecta a la libertad de formas, y al tratamiento narrativo de la historia. (...)

Quizás también tendríamos que utilizar el término postgenérico para referirnos a aquel amplio conjunto de filmes que, desde los setenta, viene marcando la difícil evolución del género. Ya que lo que encontramos en el cine no es más que un claro reflejo de este fenómeno socio-cultural que supone, en primer lugar, una crisis de las instituciones y, en segundo lugar, un cambio radical y una puesta en cuestión de los códigos y condiciones que aseguraban la comunicación.

Esta definición de lo postgenérico en torno a la crisis sociocultural surgida sobre todo a partir de la década que estudiamos, puede dar una pista más sobre este resquebrajamiento de los códigos genéricos clásicos, otrora vinculados a la política de estudios y sus unidades de producción especializadas. El cinema del período analizado puede definirse, pues, como en deriva hacia lo postgenérico.

\subsubsection{Thriller erótico-moralista y de adulterios}

Un tema especialmente recurrente en el período acotado es el del triángulo amoroso, abordado desde una perspectiva indefectiblemente moralista. La contradicción entre una mayor represión censorial y una progresiva apertura, solía condensarse en historias erótico-sentimentales, cargadas todavía de moralidad católica, ambientadas en entornos burgueses, y girando siempre alrededor de la institución matrimonial, tan enrarecida entonces a causa sobre todo de la evolución de las costumbres sexuales y de la prohibición del divorcio por el régimen franquista desde la Guerra. Así: Hembra (prohibido) (1970), del emblemático cineasta nacionalcatólico César F. Ardavín; Fieras sin jaula (1971), de Juan Logar; El ojo del huracán (1971), de José María Forqué; etcétera.

\subsubsection{Thriller psicológico}

Relatos mórbidos con un fuerte componente claustrofóbico y notorios efluvios hichcockianos, imperarán en el thriller español del "período oscuro". Así: Algo amargo en la boca (1969), de Eloy de la Iglesia (híbrido genérico, como ya se ha dicho: cruce de thriller psicológico, melodrama erótico-intimista y morboso, y parábola sociopolítica); Helena y Fernanda (1969), de Julio Diamante; Una droga llamada Helen (1970), de Umberto Lenzi; Una maleta para un cadáver (1970), de Alfonso Brescia (que introducía fuertes rasgos de ironía que lo hacían lindar con la comedia negra); etcétera... 


\subsubsection{Thriller autóctono de apología policial}

La tradición española del thriller franquista (procedente de la factoría Iquino y que conoció su esplendor en los 50) con reminiscencias del “optimismo policial” inaugurado por William Keighley, halló continuidad en el período que nos ocupa, con títulos como: Investigación criminal (1969), de Juan Bosch (estricta apología de la labor de la Brigada de Investigación Criminal); El vértigo del crimen (1970), de Pascual Cervera (el más ortodoxo continuador de esta tradición); Disco rojo (1972), de Rafael Romero Marchent (pese a su ambientación lisboeta); etcétera.

\subsubsection{Giallo}

Como consecuencia de los recientes éxitos internacionales de Dario Argento con cintas como El pájaro de las plumas de cristal, se crea (a semejanza de los numerosos imitadores de Leone en el spaghetti-western) una corriente derivada que se extiende aproximadamente hasta 1975, y que continúa en verdad la concepción del suspense y el policíaco emprendida por Mario Bava, maestro cinematográfico de aquel, y cuya criatura será conocida históricamente como giallo. El giallo (amarillo, en italiano) tomaba su nombre del color de las cubiertas de una celebérrima colección de novelas criminales sensacionalistas de kiosco, publicadas en el país transalpino. Esta corriente puede definirse como un ciclo de películas de asesinatos en serie, con una puesta en escena efectista (incluyendo casi siempre una banda sonora a base de atmósferas y formantes estridentes); resortes narrativos propios del suspense fílmico (anticipación, montaje de presagio, etc.); estetización de los crímenes y de su formalización visual (barroquismo de los encuadres y ángulos enfáticos, aunque esto no siempre se cumple...); un cierto erotismo tanático más o menos acentuado según los casos (esa ligazón sexo-muerte que obsesionaba a los surrealistas); títulos a tono con el sensacionalismo imperante (Rojo intenso, La muerte acaricia a medianoche); ciertas dosis de psicologismo, y un marcado protagonismo femenino, con elencos encabezados por féminas explosivas como Marisa Mell o Florinda Bolkan... En España, el giallo tuvo un impacto especialmente potente que ha sido obviado o ignorado por los historiadores. La nómina de títulos es, cuando menos, caudalosa: Una historia perversa (1969), de Lucio Fulci; Días de angustia (1970), de Luciano Ercoli; Las fotos de una mujer decente (1970), de Piero Sciumè; etcétera.

\subsubsection{Poliziesco}

La tradición específica del policíaco italiano es reconocible en una serie de rasgos que adquirió desde los albores de los 70: una cierta anécdota de crítica social, no siempre sincera (más bien a rebufo de la moda izquierdista de la época), una desacomplejada aclimatación realista de la forma fílmica del thriller norteamericano de acción a las condiciones ítalas; y la alargada sombra del Harry el Sucio de Don Siegel, 
dentro de discursos coyunturales contra la corrupción social y la figura del héroe solitario de métodos duros y violentos enfrentado con la impotencia del legalismo. Pero el matiz italiano al respecto estribaba en que el inexorable policía solía acabar peleando con estructuras de poder de gran fuste (mafias internacionales, redes delictivas sostenidas por algún oligarca empresarial o financiero), lo cual situaba a este cine a la izquierda del polémico tándem Siegel-Eastwood... En España, donde la forma italiana o italianizante del policíaco tuvo su peso, la aludida anécdota política hubo de ser, por fuerza, mucho más recatada y ambientada en el país coproductor. El poliziesco hispano-italiano está integrado por obras como Los fríos ojos del miedo (1971), de Enzo G. Castellari; El consejero (1973), de Alberto de Martino; Los mil ojos del asesino (1973), de Juan Bosch; etcétera.

\subsubsection{Polar}

La tradición propiamente gala del policiaco, conocida como polar, también hallará cabida en varias coproducciones con España a lo largo del "período oscuro": tal será el caso de Jaque mate (1969), de Claude Carliez; Las bellas (1969), de Pierre Chenal; Que esperen los cuervos (1970), de Jean-Pierre Desagnat; El affaire Dominici (1972), de Claude Bernard-Aubert; y Tráfico de mujeres (1974), de Roger Hanin.

\subsubsection{Krimi}

Por su parte, la tradición de cine criminal teutón, conocido como Krimi, e implantado en la RFA a partir sobre todo de adaptaciones fílmicas de Edgar Wallace, con una serie de rasgos generalmente consustanciales (ambientación cosmopolita, tramas enredadas y repletas de intrigas extrañas y de personajes enigmáticos y estrambóticos, oscuros villanos que parecen remitir a los enmascarados de los viejos seriales de Louis Feuillade...), conocerá también su connubio con la cinematografía española, si bien este será muy escaso. A saber: Los crímenes de Petiot (1972), de José Luis Madrid; Una secretaria para matar (1972), de Carl Zeiter (bajo el seudónimo Douglas Fithian); y Orden de INTERPOL: sin un momento de tregua (1973), del emblemático Alfred Vohrer, en su día un símbolo viviente del cine alemán de género, sobre todo del western y el Krimi.

\subsubsection{Derivados de Diez negritos y Las diabólicas}

Una fórmula recurrente en el thriller español del "Período Oscuro" es el de los derivados temático-argumentales del Diez negritos de Agatha Christie: un lugar cerrado, claustrofóbico, donde varios personajes reunidos, culpables todos de crímenes y abyecciones encubiertas, van siendo eliminados por un asesino misterioso: Un silencio de tumba (1972), de Jesús Franco; El asesino está entre los trece (1973), de Javier Aguirre; La noche de los asesinos (1973), de Jesús Franco. Asimismo, se 
produce una adaptación real de dicha novela dentro del período: el Diez negritos (1974), de Peter Collinson, coproducción internacional cuatripartita (España-RFAItalia-Francia) con un fastuoso reparto (Oliver Reed, Elke Sommer, Richard Attenborough, Gert Fröbe, Teresa Gimpera, Herbert Lom...) Otra fórmula que se repite en la etapa estudiada es la de los derivados de Las diabólicas de Boileau-Narcejac (y es de suponer que también de su celebérrima adaptación cinematográfica por HenriGeorges Clouzot): un triángulo amoroso en que la o el amante propone al marido o la esposa aliarse para asesinar al cónyuge. Así: la muy hitchcockiana Helena y Fernanda (1969), de Julio Diamante; Una droga llamada Helen (1970), de Umberto Lenzi; Historia de una traición (1971), de José Antonio Nieves Conde; Homicidio al límite de la ley (1971), de Tonino Ricci, coescrito por Forqué y Azcona; etcétera.

\subsubsection{Revival del cine de gángsters}

Asimismo, se repite en el thriller del "Período Oscuro", un revival del cine de gángsters, nacido del gran éxito internacional de Bonnie \& Clyde (1967), de Artur Penn. Así: América rugiente (1969), de Alfio Cantabiano (cuyo título es un homenaje a The roaring twenties (1939), de Walsh); La banda de los tres crisantemos (1969), de Ignacio F. Iquino; El regreso de Al Capone (1969), de José María Zabalza; Tiempos de Chicago (1969), de Julio Diamante; y iViva América! (1969), de Javier Setó.

\subsubsection{Parodias, metalenguaje y autoconsciencia}

Al hilo de las anteriores afirmaciones sobre lo postgenérico, se dan varios casos de autoconsciencia metagenérica y metalingüística en el cine de la época. El más elemental es el de un cierto auge de la comedia macabra, con títulos como Me debes un muerto (1971), de Sáenz de Heredia (que, sobre la falsilla del Extraños en un tren hitchcockiano, parodiaba el género negro, el furor epocal por lo sobrenatural y fantaterrorífico, y la propia tradición autóctona del musical folclórico...), o Black Story (1971), de Lazaga (donde la trama se articulaba en las fantasías literario-criminales de un infeliz españolito medio), entre otras. Casos más curiosos se darán con las incursiones en el territorio del cine-cómic, entonces en boga gracias a cineastas como Vadim, Bava o Lenzi. Así, Crimen imperfecto (1970), encargo de Lazaga a FernánGómez, en que este parafraseaba la estética chillona y de colores planos del tebeo Bruguera; y Sexy Cat (1972), de Julio Pérez Tabernero.

Otros cineastas empleaban el punto de partida del thriller para realizar ejercicios autorales: así, Vicente Aranda con Cadáver exquisito/ Las crueles (1969), inspirado en los experimentos de deconstrucción temporal y lingüística del relato por Resnais, Robbe-Grillet y el Nouveau Roman; etcétera. 


\subsubsection{Pulp y novelística popular}

Aún eran los tiempos dorados de Marcial Lafuente Estefanía, Silver Kane, Corín Tellado, Curtis Garland. El influjo de la novela popular de kiosco, a la sazón tan en boga en nuestro país sobre todo desde los años 20 (con las novelas del Caballero Audaz, de Canellas Casals y de Hoyos y Vinent, por ejemplo), y precedida por los folletines decimonónicos de Fernández y González, también dejó su impronta (abiertamente americanizada desde el rotundo éxito de la serie de novelas FBI en los años 50) en el celuloide patrio. Tal es el caso de las adaptaciones (sobre pulps preferentemente españoles, pero también foráneos): Jaque mate (1969), de Claude Carliez, sobre un original de Claude Rank; El muerto hace las maletas (1970), de Jesús Franco, sobre una novela del germano-occidental Bryan Edgar Wallace; Que esperen los cuervos (1970), de Jean-Pierre Desagnat, sobre André Lay; etcétera.

\section{CONCLUSIONES}

1) Se ha corroborado la operatividad de la periodización histórica 1969-1975 para el estudio de la última etapa de la cinematografía del franquismo (el "período oscuro” del cine español) y el análisis de la crisis coetánea del cinema autóctono, tanto en lo concerniente a su aparato político-administrativo, académico (EOC) y sindical (ASDREC como ejemplo significativo), como a su estructura económica y empresarial.

2) Se ha apreciado el crecimiento del consumo de receptores de televisión en el período, y su posible incidencia en el simultáneo declinar de la economía cinematográfica.

3) Se ha podido ver la inestabilidad y decadencia del cine de género y de las coproducciones internacionales, durante el "Período Oscuro."

4) Se ha ilustrado la decadencia del parque de salas de exhibición durante la etapa estudiada.

5) Se ha comprobado, e ilustrado con ejemplos, el ascendiente comercial y el sólido negocio y entramado empresarial en torno al cine de género, durante el período.

6) Se ha discutido y problematizado adecuadamente la denominación cine de subgéneros, para llegar a la conclusión de que el cine de género periférico (no-hollywoodiense) de bajo presupuesto, está pendiente de una denominación científica pertinente.

7) Se ha hallado que, inesperadamente, los films centrados en tramas delictivas y de intriga (lo que se entiende por thriller) alcanzan -al menos, en lo que se ha podido encontrar a través de diccionarios, anuarios, cronologías, catálogos, bases de datos y revistas-, la fabulosa cifra de 147 films en tan sólo siete años que abarca el período analizado. Asimismo, se ha realizado un análisis cuantitativo de la evolución del thriller en la etapa analizada, con detenimiento es- 
pecífico también en las coproducciones internacionales y el procedimiento de rodaje Techniscope.

8) Se ha concluido en la importancia del procedimiento Techniscope en el cine de género de la época, lo que proporciona nuevos elementos de juicio para historiar y analizar este cine.

9) Se han inventariado las diversas categorías y tendencias que adopta el thriller español del "período oscuro", lo que constata su carácter cosmopolita y capaz de rebasar nuestras fronteras, fundamentalmente por la abierta impregnación de corrientes y modas internacionales, y proporciona pistas sobre su complejidad referencial y sobre su alcance ideológico y sociológico-cultural, de cara a posibles futuros análisis en este sentido. Igualmente, se ha relacionado esta complejidad y enmarañamiento de categorías y tendencias, con la crisis de la política de géneros cinematográficos en los años 70 , y la deriva hacia lo postgenérico en el cine español.
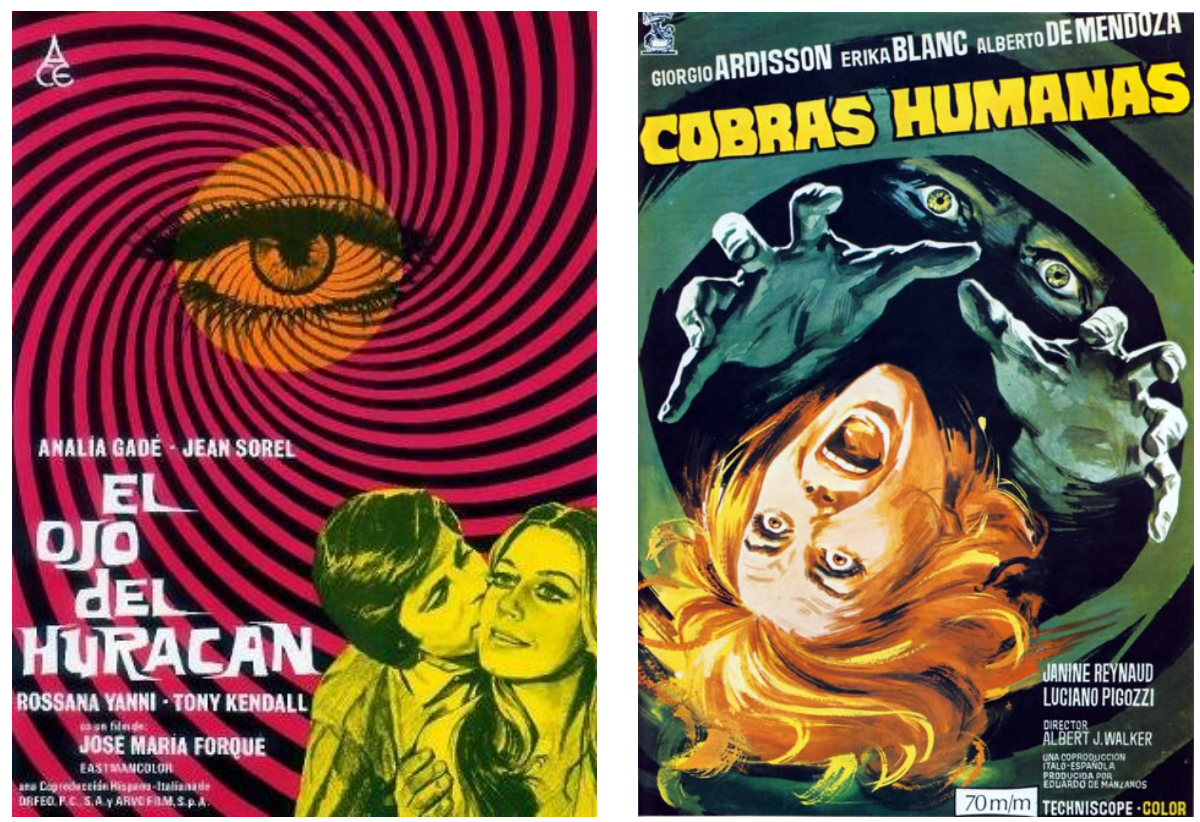


\section{BIBLIOGRAFÍA}

ABAJO DE PABLOS, Juan Julio (2001): Los thrillers españoles. Valladolid: Fancy.

CEBOLLADA, Pascual (1996): Enciclopedia del cine español, volumen 2. Cronología. Barcelona: Ediciones del Serbal.

Cineinforme. Año 1973.

DE MIGUEL, Casilda (1991): Lo genérico y lo postgenérico. Cuadernos cinematográficos, 7, pp. 93-98. Universidad de Valladolid.

DE ZÁRRAGA, José Luis (1975): La estructura económica del cine español, en V.V.A.A. (1975): 7 trabajos de base sobre el cine español. Valencia: Fernando Torres Editor, pp. 13-45.

GASCA, Luis (1998): 100 años de cine español. Barcelona: Planeta.

GUBERN, Román (1974): "Prólogo", en EQUIPO CARTELERA TURIA: Cine español, cine de subgéneros. Valencia: Fernando Torres Editor, pp. 12-15.

HERNÁNDEZ, Marta, y REVUELTA, Manolo (1976): 30 años de cine al alcance de todos los españoles. Madrid: Zero.

HUERTA FLORIANO, Miguel Ángel, y PÉREZ MORÁN, Ernesto (2012): El cine de barrio del tardofranquismo. Reflejo de una sociedad. Madrid: Biblioteca Nueva.

HUESO MONTÓN, Ángel Luis (1991): La exhibición cinematográfica española: Datos para un análisis. Cuadernos cinematográficos, 7, pp. 9-21. Universidad de Valladolid.

MEDINA, Elena (2000): Cine negro y policíaco español de los años 50. Barcelona: Laertes.

MONTERDE, José Enrique (1992): Veinte años de cine español 1973-1992. Un cine bajo la paradoja. Barcelona: Paidós.

PÉREZ BOWIE, José Antonio (ed.) (2013): La noche se mueve. Madrid: Libros de la Catarata.

RIAMBAU, Esteve, y TORREIRO, Casimiro (1998): Guionistas en el cine español. Quimeras, picarescas y pluriempleo. Madrid: Cátedra/Filmoteca Española.

RIAMBAU, Esteve, y TORREIRO, Casimiro (2008): Productores en el cine español. Estado, dependencias y mercado. Madrid: Cátedra/Filmoteca Española.

RUEDA LAFFOND, José Carlos (2005): La televisión en España: expansión y consumo social, 1963-1969”. Anàlisi: Quaderns de Comunicació y Cultura, 32, pp. 45-71. Universitat Autònoma de Barcelona. Recuperado de http://ddd.uab.cat/pub/analisi/02112175n32/02112175n32p45.pdf

TORREIRO, Casimiro, en GUBERN, Román, et al. (2009): Historia del cine español. Madrid: Cátedra.

VALLÉS COPEIRO DEL VILLAR, Antonio (1992): Historia de la política de fomento del cine español. Valencia: Filmoteca de la Generalitat Valenciana.

V.V.A.A. (1975): 7 trabajos de base sobre el cine español. Valencia: Fernando Torres Editor, pp. 13-45. 